\title{
PARÂMETROS ACÚSTICOS DE QUALIDADE VOCAL PRÉ E PÓS REALIZAÇÃO DE EXERCÍCIO DE TRATO VOCAL SEMIOCLUÍDO
}

\author{
Diego Henrique da Cruz Martinho*, Ana Carolina Constantini
}

\begin{abstract}
Resumo
Trata-se de uma pesquisa quantitativa de caráter transversal com a participação de 26 coristas (SATB) que realizaram os seguintes ETVSO: fonação em tubo de menor resistência (LaxVox®), finger kazoo e fonação com canudo de alta resistência. Foi realizada gravação pré e pós execução das técnicas, aplicado questionário de autoavaliação vocal e realizada extração e análise de um conjunto de parâmetros acústicos das amostras de fala.
\end{abstract}

\section{Palavras-chave: \\ Qualidade da Voz, Treinamento da Voz, Canto Popular}

\section{Introdução}

Os exercícios de trato vocal semiocluído (ETVSO) são amplamente utilizados na rotina fonoaudiológica tanto na prevenção de disfonias quanto no processo de reabilitação. Os principais efeitos desses exercícios são: alongamento do trato vocal, mudança na impedância acústica, equilíbrio das pressões sub e supraglótica, aumento da interação fonte e filtro, o que faz com que a energia retroflexa dos ETVSO permita o afastamento das pregas vocais durante a vibração, além do favorecimento de uma voz mais rica em harmônicos e melhora da propriocepção, aumentando as sensações durante e após os exercícios ${ }^{(1)}$. Esses exercícios, no geral, melhoram a qualidade vocal que pode ser avaliada em um indivíduo por meio da autopercepção do sujeito, análise perceptivo-auditiva e análise acústica por meio de softwares.

O objetivo do estudo foi analisar um conjunto de parâmetros acústicos pré e pós realização, por cantores de um coro cênico amador, de três exercícios de trato vocal semiocluído: a fonação em tubo de menor resistência (LaxVox®), finger kazoo e fonação com canudo de alta resistência. Correlacionar achados acústicos e de autopercepção da qualidade vocal.

\section{Resultados e Discussão}

A análise acústica da vogal sustentada [a] permitiu confirmar quantitativamente os resultados da autoavaliação vocal dos sujeitos(2), a partir da análise das medidas de F0, jitter, shimmer e Proporção Harmônico Ruído (HNR). Foram encontradas modificações no pitch após a execução dos exercícios, bem como o aumento do número de harmônicos devido ao alongamento do trato vocal, esses achados vão de encontro com a literatura atual(3,4,5). A maioria dos sujeitos apresentou melhora da qualidade vocal após realização de ambas as técnicas. No grupo de vozes graves, foi evidenciada melhora mais significativa após a realização da técnica de fonação em tubo de menor resistência, com melhora da HNR ( $p$-valor= 0,001 ) e no Jitter ( $p$-valor $=0,038$ ). No grupo de vozes agudas foi evidenciada melhora mais significativa após a execução da fonação em canudo de alta resistência. Os sujeitos apresentaram mudanças estatisticamente significantes quanto ao aumento da frequência fundamental ( $p$-valor $=0,002)$, melhora do Jitter $(p$-valor= $0,049)$, do Shimmer ( $p$-valor $=0,013)$ e da HNR ( $p$-valor= 0,000032).

O estudo demonstrou até agora que, apesar das três técnicas serem parte da mesma classe de exercícios, seus efeitos são variados e devem ser adequados a cada tipo de voz. A fonação em tubo de menor resistência promove 0 alongamento do trato vocal que está diretamente associado a diminuição do pitch(1), justificando a preferência das vozes graves por esse exercício. O canudo de alta resistência gera um da pressão subglotal devido ao novo ponto de constrição criado pelo exercício(6), facilitando assim um aumento do pitch o que justifica a preferência das vozes agudas por esta técnica.

Evidencia-se a necessidade de conhecer melhor os efeitos de cada exercício, visto que ainda nenhum estudo os compara à classificação vocal ou ao tamanho do trato vocal do sujeito. Além disso, destaca-se a necessidade de mais estudos que mensurem a impedância acústica proveniente dos ETVSO, bem como onde essa energia se concentra em cada exercício.

\section{Conclusões}

Os resultados da autopercepção dos sujeitos classificaram o tubo LaxVox® como mais adequado às vozes graves e menos adequado às agudas, enquanto que o canudo de alta resistência se adequou melhor às vozes agudas e menos às graves ${ }^{(2)}$. Os dados obtidos por meio da análise acústica vão de encontro aos achados da autopercepção dos sujeitos.

\section{Agradecimentos}

Agradecemos aos cantores do Coral Unicamp Zíper na boca por cederem suas vozes para essa pesquisa, à regente Dra. Vivian Nogueira Dias e à preparadora vocal Ruxelli Bergamaschi. Agradecemos também FAPESP pelo apoio financeiro.

\footnotetext{
1 Cielo, C. A. et al. "Exercícios de trato vocal semiocluído: revisão de literatura". Revista CEFAC, v. 15, n. 6, p. 1679-1689, 2013.

2 Martinho, D. H. C.; Leite Neto, L.; Constantini, A. C. Autopercepção do Efeito Imediato de ETVSO em Coralistas Amadores. In: XXV Congresso Brasileiro De Fonoaudiologia, 2017, SALVADOR. Sessão de Pôsteres, 2017. p. 9446.

${ }^{3}$ Fantini, M. et al. Voice Quality After a Semi-Occluded Vocal Tract Exercise With a Ventilation Mask in Contemporary Commercial Singers: Acoustic Analysis and Self-Assessments. Journal of Voice, 2016.

${ }^{4}$ Manternach, J. N. et al. Effects of a Straw Phonation Protocol on Acoustic Measures of an SATB Chorus Singing Two Contrasting Renaissance Works. Journal of Voice, 2017.

5 Onofre, F. et al. Measurements of the Acoustic Speaking Voice After Vocal Warm-up and Cooldown in Choir Singers. Journal of Voice, v. 31, n. 1, p. 129. e9-129. e14, 2017.

6 Andrade, P. A.. et al. "Electroglottographic study of seven semi-occluded exercises: LaxVox®, straw, lip-trill, tongue-trill, humming, hand-over-mouth, and tongue-trill combined with hand-over-mouth. Journal of Voice, 2014; v. 28, n. 5, p. 589-95.
} 